\title{
Extraction and Stability of Anthocyanins Present in the Skin of the Dragon Fruit (Hylocereus undatus)
}

\author{
María de Lourdes Vargas y Vargas ${ }^{1}$, Jorge Abraham Tamayo Cortez ${ }^{1}$, Enrique Sauri Duch ${ }^{1}$, \\ Andrés Pech Lizama ${ }^{1}$, Carlos Hernán Herrera Méndez ${ }^{2 *}$ \\ ${ }^{1}$ Research and Postgraduate Division, Instituto Tecnológico de Mérida, Mérida, Mexico; ${ }^{2}$ Agroindustrial Engineering Department, \\ Campus Celaya-Salvatierra, Universidad de Guanajuato, Salvatierra, México.

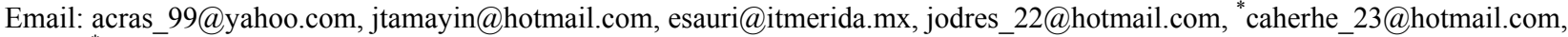 \\ *chmendez@celaya.ugto.mx
}

Received September $3^{\text {rd }}, 2013$; revised October $3^{\text {rd }}, 2013$; accepted October $10^{\text {th }}, 2013$

Copyright (C) 2013 María de Lourdes Vargas y Vargas et al. This is an open access article distributed under the Creative Commons Attribution License, which permits unrestricted use, distribution, and reproduction in any medium, provided the original work is properly cited. In accordance of the Creative Commons Attribution License all Copyrights (C) 2013 are reserved for SCIRP and the owner of the intellectual property María de Lourdes Vargas y Vargas et al. All Copyright (C) 2013 are guarded by law and by SCIRP as a guardian.

\begin{abstract}
The extraction of anthocyanins present in the skin of the dragon fruit was performed using trifluoroacetic acid (TFA) plus a mixture of methanol, acetic acid and water; the anthocyanins were then purified with a LC-18 cartridge, using methanol acidified with TFA as eluent, reaching concentrations of $44.3865 \pm 1.3125 \mathrm{mg} / 100 \mathrm{~g}$ of sample. The extracts were put through stability tests under different storage conditions, modifying the $\mathrm{pH}$ of the extracts ( $\mathrm{pH}$ of 1,4 and 6 ), the temperature $\left(4^{\circ} \mathrm{C}, 25^{\circ} \mathrm{C}\right.$ and $\left.68^{\circ} \mathrm{C}\right)$ and the absence and presence of light for a time period of 4 days; the tests indicated that anthocyanins remain more stable at a temperature of $4^{\circ} \mathrm{C}$ with a $\mathrm{pH}$ of 4 in the absence of light, retaining up to $80 \%$ of the pigment. Three anthocyanins were partially identified in the extracts by high performance liquid chromatography (HPLC); they were: cyanidin 3-O-glucoside, cyanidin 3,5 O-glucoside and pelargonidin 3,5 O-glucoside.
\end{abstract}

Keywords: Anthocyanins; Dragon Fruit; Stability

\section{Introduction}

Anthocyanins are water-soluble phenolic compounds that are present in a large number of vegetable products, and are responsible for a wide range of colors from colorless to purple [1]. They are located mainly in the skin of fruits such as apples, pears, grapes, blackberries and plums; in vegetables such as cabbage and purple onions; and in flowers such as Jamaica and roses. Although they contain few chromophore groups, more than 540 naturally occurring anthocyanidic pigments have been identified [2] The role they play in plants is to attract living beings, especially insects and birds, for pollination and seed dispersal purposes [3]. The color differences between fruits, flowers and vegetables depend on the nature and concentration of the anthocyanins they contain. Anthocyanins are derivatives of the 2-fenil benzopyrylium cation; due to their poor solubility in water, they are not found freely in nature, but only in their glycosylated form, cya-

\footnotetext{
*Corresponding author.
}

nidin-3-glucoside being one of the most abundant [4]. In fruits, anthocyanins are preferentially located in the skin and occasionally in the pulp; they may contain a single type of pigment, as in the apple (Pyrus malus) and redcurrant (Ribes rubrum), which contain only cyanidin. In contrast, fruits such as grapes $(V$. vinifera $)$ and blueberries (Vaccinium myrtillus) contain a combination of five of the six common anthocyanidins. The variation of anthocyanins in fruits is more limited than in flowers, where 50 different ones have been identified, of which the most common is cyanidin, followed, in order of importance, by peonidin, delphinidin, pelargonidin, malvidin and petunidin $[5,6]$. The different types of anthocyanins depend on the number of hydroxyl groups, sugars, aliphatic groups and aromatic acids attached to the basic structure of anthocyanins. The particular color of each anthocyanin depends on the number and orientation of the hydroxyl and methoxyl groups in the molecule [7]. Increases in hydroxylation produce a displacement towards blue hues, while increases in methoxylation pro- 
duce red colors $[8,9]$. Numerous studies have been carried out, the main objective of which has been the chemical characterization of anthocyanins in various natural products, with the aim of using these phenolic compounds as alternatives to synthetic dyes used in the food industry $[10,11]$. This type of pigment is relatively little used, only in some dairy products, ice cream, candy, baked goods and canned vegetables. Likewise, interest in anthocyanins has increased not only due to the color they give to the products that contain them, but because of their possible role in decreasing heart disease, cancer and diabetes, their antiinflammatory effects and their capacity to improve visual sharpness and cognitive behavior [1214]. Therefore, in addition to their role as colorants, anthocyanins are potential agents for obtaining value-added products for human consumption due to their capacity to act as natural antioxidants [15]. Knowledge of the chemistry of anthocyanins can be used to minimize their degradation through a suitable choice of the processes and a selection of the anthocyanin pigments that present greater stability for the intended application. Despite the advantages of anthocyanins as potential substitutes of synthetic dyes, they are labile compounds, which, together with factors such as their low stability and the lack of available plant material, limit their commercial application $[16,17]$. The dragon fruit (Hylocereus undatus) is an exotic fruit worldwide, as it is unknown in many countries, which creates a potential for diversifying by making different types of food products with high nutritional value. The fruit is an ovoid berry, rounded and elongated, ten to twelve inches in diameter; the skin is purple-red to yellow-red in color, covered with bracts (leafy scales) of yellowish green color; its weight varies from 350 to 750 $\mathrm{g}$ and has a delicious flavor [18]. Its flesh is white with abundant dark brown or black seeds distributed throughout the fruit. In recent years, several studies have been made on the dragon fruit, evaluating its key features, the changes that occur during ripening, post-harvest management and conservation [19]. However, there is not enough information about the types of pigments found in the skin of the fruit and the relation between the color changes in the skin and the postharvest ripening of the fruit. After harvest, while chlorophyll decomposes, there is a synthesis of other pigments that are responsible for the characteristic red color of the mature dragon fruit; small amounts of carotenoids appear, reaching a peak in the yellow-pink zones and decreasing when the fruit reaches its deeper color; this color coincides with the highest concentrations of betalains and anthocyanins, the latter (anthocyanins) reaches higher concentrations than the carotenoids and betalains [20]. One of the important aspects of the fruit is the intensity of the red to violet color that presents when mature, which means it has a high content of antioxidants, especially of the anthocyanins group.
The skin of the dragon fruit can be an important source of natural colorants, as restrictions on the use of synthetic food colorants have led to a rising interest in the use of anthocyanins and flavonoids as food colorants, as well as for pharmaceuticals products, cosmetics and the like [3]. The aim of this work was to quantify the anthocyanin content present in the skin of the dragon fruit (Hylocereus undatus) and to assess the stability of this pigment under different storage conditions for its possible use as food colorant.

\section{Materials and Methods}

\subsection{Raw Material}

The dragon fruits (Hylocereus undatus) were purchased directly from a local producer, selecting those that showed a red coloration in full and were free of damage. The fruits were taken at different harvest times, making a total of 5 samples, each with 6 experimental units. The skin was separated manually with a stainless steel knife, removing any hint of flesh; it was subsequently cut and placed in trays for drying at $45^{\circ} \mathrm{C}$ in an oven; the dried skin was pulverized before being stored frozen until use.

\subsection{Measurement of Color}

The color of the skin of the dragon fruits was determined using a tristimulus colorimeter, obtaining the values of $L^{*}, a^{*}$ and $b^{*}$. $L^{*}$ measures the brightness of color, ranging from $0=$ black to $100=$ white; $a^{*}$ can be positive (red) or negative (green); and $b^{*}$ can be positive (yellow) or negative (blue). The $a^{*}$ and $b^{*}$ values were converted to tones according to the equation proposed by McGuire: Tone $=\tan ^{-1}\left(b^{*} / a^{*}\right)[21]$.

\subsection{Extraction of Anthocyanins}

We followed the method proposed by Peña et al. [22], which consisted of adding $20 \mathrm{ml}$ of $1 \%$ trifluoroacetic acid in methanol to $0.5 \mathrm{~g}$ of pulverized skin, refrigerating for 24 hours, then decanting the supernatant; a mixture of methanol was added to the residue: acetic acid: water (10:1:9), and kept under constant stirring for 24 hours at room temperature, after which time the supernatant was decanted and the residue was washed with $20 \mathrm{ml}$ of the same mixture and under the same conditions of time and temperature. At the end of each extraction, the volume of the decanted supernatant was measured and filtered with Whatman paper no. 42 of $70 \mathrm{~mm}$. The extracts obtained from each wash were kept at $4^{\circ} \mathrm{C}$ until reading.

\subsection{Quantification of Anthocyanins}

The quantification was performed spectrophotometrically, reading each of the extracts obtained previously at a wavelength of $520 \mathrm{~nm}$; the total anthocyanin concentra- 
tion, as $\mathrm{mg}$ of anthocyanins per $100 \mathrm{~g}^{-1}$ of skin, was calculated using the volume, absorbance and weight of the sample data, using an extinction coefficient of 29,600 $1 / \mathrm{mol}^{-1} \cdot \mathrm{cm}^{-1}$ and a molecular weight of $445.2 \mathrm{~g} / \mathrm{mol} \mathrm{[23].}$

\subsection{Purification and Partial Identification of Anthocyanins by HPLC}

For purification of the anthocyanins, the extract obtained from the first extraction with $1 \%$ trifluoroacetic acid (TFA) in methanol was passed through a Supelclean LC-18 cartridge, the purpose of which is to separate relatively hydrophobic compounds such as anthocyanins from sugars and acids. The cartridge was conditioned by adding $4 \mathrm{ml}$ of acidified water, followed by $4 \mathrm{ml}$ of acidified methanol and $2 \mathrm{ml}$ of acidified water again to remove the remaining methanol. One $\mathrm{ml}$ of the extract is placed in the cartridge and the anthocyanin is eluted through the cartridge using acidified methanol with TFA at a $\mathrm{pH}$ of 1 . A high performance liquid chromatograph (HPLC), Perkin Elmer, C200, with UV-visible detector was used for the analysis of the samples, using a Brownlee Analytical C18 reverse phase column of $150 \times 4.6$ $\mathrm{mm}$. The separation was performed with gradient elution at a flow rate of $1 \mathrm{ml} / \mathrm{min}$, using acidified water with $0.1 \%$ TFA (v/v) as mobile phase A, and HPLC grade acetonitrile with $0.035 \%$ formic acid $(\mathrm{v} / \mathrm{v})$ as phase $\mathrm{B}$. The injection volume was $20 \mu \mathrm{l}$. The following gradients were used: $10 \%-11 \%$ of $\mathrm{B}$ in $12 \mathrm{~min}, 11 \%-12 \%$ in 8 $\min , 12 \%-13 \%$ in $5 \mathrm{~min}, 13 \%-18 \%$ in $10 \mathrm{~min}$, and $18 \%$ of B maintained for $25 \mathrm{~min}$. The anthocyanins were analyzed with a visible detector at $520 \mathrm{~nm}$. Before injecting it, the sample was filtered through a $0.45 \mu \mathrm{m}$ acrodisc (Millipore, Bedford, MA). The identification of the anthocyanins was performed using commercial standards of known retention times. The standards used were: Malvidin, Cyanidin and Pelargonidin (SIGMA).

\subsection{Stability of the Pigment}

The stability of the pigments was tested in extracts of anthocyanin at different temperatures, $\mathrm{pH}$ and light, according to the factorial design described in Table 1; the values were randomly assigned. The $\mathrm{pH}$ of the extracts was adjusted with $\mathrm{HCl}$ and $\mathrm{NaOH} 1 \mathrm{~N}$; glass flasks were used for storage, each containing $10 \mathrm{ml}$ of the extract;

Table 1. Storage conditions for evaluating the stability of anthocyanin extracts.

\begin{tabular}{ccc}
\hline Temperature $\left({ }^{\circ} \mathbf{C}\right)$ & pH & Light \\
\hline 4 & $1,4,6$ & Absence and presence \\
25 & $1,4,6$ & Absence and presence \\
68 & $1,4,6$ & Absence and presence \\
\hline
\end{tabular}

absorbance was determined to these extracts every 7 days for a period of 4 weeks. The experiment was performed in duplicate.

\subsection{Experimental Design}

A factorial experimental design with 3 factors was employed, with 3 levels for $\mathrm{pH}$ and temperature, and 2 levels of light (absence and presence of light). The statistical analysis of the data generated was done using the package "STATGRAPHICS XV.I Centurion", performing an analysis of variance and Duncan's multiple range tests, considering a completely randomized experiment.

\section{Results and Discussion}

\subsection{Measuring Color}

Many of the studies on anthocyanins in fruits that evaluate color changes and correlate them with changes in anthocyanin content, use the $\mathrm{L}^{*}$ and Tone system $[24,25]$. According to McGuire [21], hue angle and chroma are better understood aspects in the producer-consumer chain; this is associated to the fact that the human eye does not separate colors into their components but sees them as a whole. Different statistical analyzes were performed with the values of $\mathrm{L}^{*}$ per experimental unit and per sample to determine the correlation between brightness and date of harvest, and whether this has any relationship with the content of compounds in the skin of the dragon fruit. Color measurements in the skin of the dragon fruit (Figure 1) indicated that there was no significant difference in the parameter $\mathrm{L}^{*}$ between the samples and between each dragon fruit, with a $95 \%$ confidence level $(p>0.05)$, and an average value of $19.12 \pm 2.78$. With respect to tone (hue angle), all dragon fruits were in quadrant 1 of the tristimulus scale $\mathrm{L}^{*} \mathrm{a} * \mathrm{~b}$, which in turn means that they were between the red and the yellow axes, reaching purplish red tones. According to ANOVA, there was no significant difference between the dragon fruits of each sample and the hue angle. With respect to the analysis between the samples, there is a statistically significant variation between samples $1-5,2-4,2-5$ and $3-5$, as they exceed the maximum and minimum limits in the mean

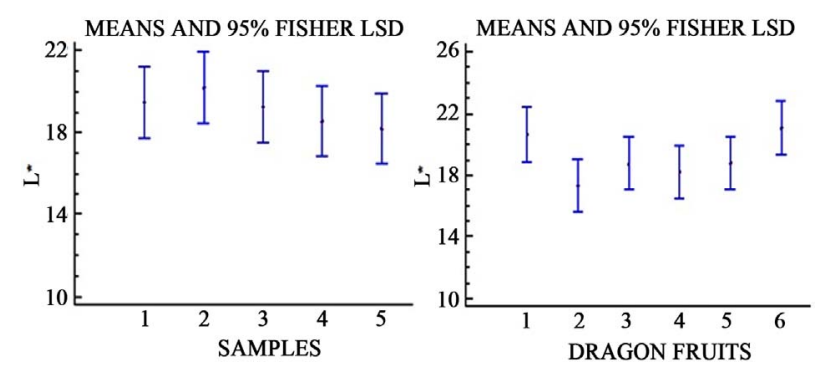

Figure 1. Comparison of brightness values per sample and dragon fruit. 
comparison, which can be seen in Figure 2. The difference presented by these samples is due to the variation in climate, because at the time of the samplings 4 and 5, the rain that fell during the time of harvest was higher, which could have an effect on the color of the skin.

\subsection{Extraction and Quantification of Anthocyanins}

Table 2 shows the average composition with respect to the fractions found in the fruit, both for the edible part (pulp and seeds) and for the skin. Nerd et al. [26] report values of $32.5 \%$ for the skin, which resemble the values found for the dragon fruits of this study. However, the average weight of the whole fruit is similar to that reported by Centurión et al. [19], who obtained dragon fruits with a weight of $463.7 \mathrm{~g}$, with variations regarding the pulp and the skin, as they mentioned a pulp weight of $368.91 \mathrm{~g}$ and a skin weight of $94.8 \mathrm{~g}$, the latter representing a value of $20.4 \%$. This suggests that the fruits of this work had a thicker skin. The average content of anthocyanins from the skin of dragon fruits harvested in different seasons was $45.15 \pm 0.5117 \mathrm{~g} / 100 \mathrm{~g}$ of dry dragon fruit skin. The quantification results of this study are similar to those found in raspberry by Antonne and Karjalinen [27], who found values of 19 and $51 \mathrm{mg} / 100 \mathrm{~g}$ of fresh fruit; they are also similar to the values obtained by Peña et al. [22] which range from 28.7 to $55.6 \mathrm{mg} / 100 \mathrm{~g}$ of fresh fruit. These variations may be due to the solvents used or to the methodology used to extract the compound. The analysis of variance showed no signifi-

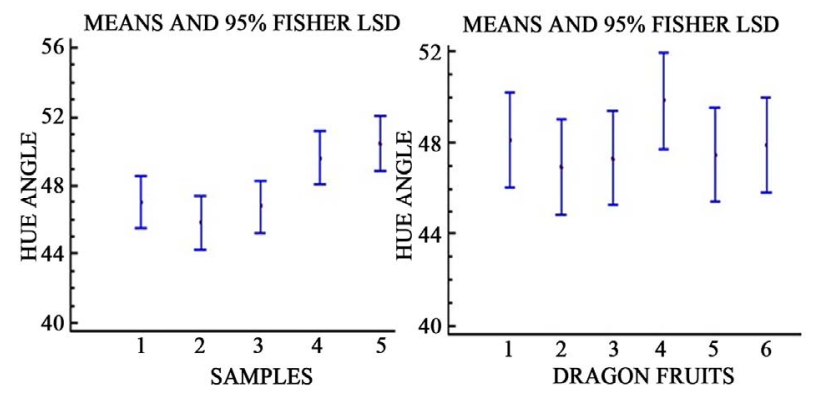

Figure 2. Comparison of means of the hue angle between samples and dragon fruits.

Table 2. Average composition of the parts of the dragon fruit (Hylocereus undatus).

\begin{tabular}{ccc}
\hline & \multicolumn{2}{c}{ Average weight of the parts of the dragon fruit } \\
\cline { 2 - 3 } & Average weight (g) & Percentage \\
\hline Whole fruit & $463.21 \pm 59.74$ & 100 \\
Skin & $148.10 \pm 31.46$ & 31.97 \\
Pulp and seeds & $315.11 \pm 54.14$ & 68.027 \\
\hline
\end{tabular}

cant difference in anthocyanin content between the dragon fruits analyzed at different sampling times (Figure 3). The average yield of dragon fruit skin was 319.72 $\mathrm{g}$ per kilogram of dragon fruit; anthocyanin content was $45.69 \mathrm{mg} / 100 \mathrm{~g}$ of dry skin; therefore, a total of $0.1460 \mathrm{~g}$ of anthocyanins was extracted per kilogram of skin. The dragon fruit is thus a suitable source of anthocyanins, since they are obtained solely from the skin, unlike Aguilera et al. [23], who report, for the purple fig of the Mission variety, values $0.295 \mathrm{~g}$ per kilogram of whole fruit. The extraction method must be one that allows recovering the greatest possible amount of anthocyanins with minimum losses due to enzymatic and non-enzymatic changes. Anthocyanins are generally isolated in acidic media. Among the methods that have been tested for extracting anthocyanins from various natural sources, it was found that using methanol acidified with $1 \%$ TFA as an extraction solvent, the amount of pigment extracted increases greatly, while maintaining the stability of the anthocyanins [28]. The efficiency of extraction with TFA is attributed to the low $\mathrm{pH}$ that is reached in the system (about 1.3), to the higher solubility of anthocyanins in methanol and to the use of completely pulverized samples, which increases the contact surface of the particles in the solvent. The powdered skin of dragon fruit is subjected to extraction in the darkness for 12 hours with overnight stirring in the extraction solvent to allow the diffusion of anthocyanins through the cell membranes and to obtain, during the first extraction, a high concentration of anthocyanins; the additional extraction solvent is required to wash the residue of anthocyanins [29].

\subsection{Stability of Anthocyanin Pigments}

The behavior (Figure 4) of the anthocyanin extracts under different storage conditions is to decrease in the first week and then remain more stable from the second week of storage, finding no significant difference $(p=0.05)$ between the samples stored at $4^{\circ} \mathrm{C}$ both in the presence and absence of light, while at $25^{\circ} \mathrm{C}$, in the absence of light, the samples displayed similar values to those stored

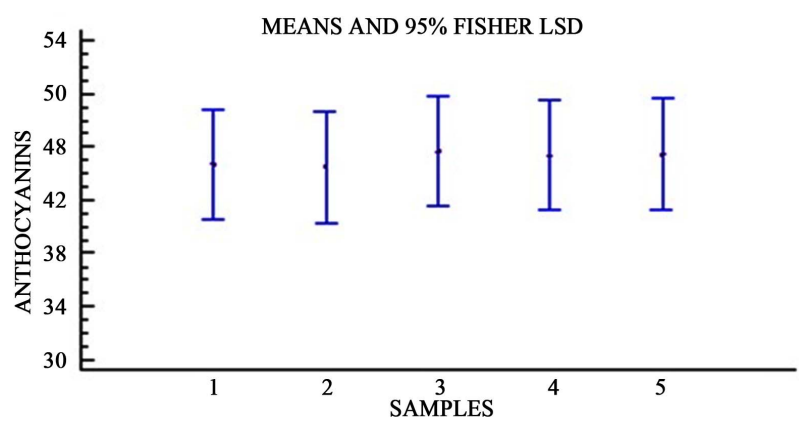

Figure 3. Average values of total anthocyanins ( $g$ of anthocyanins $/ 100 \mathrm{~g}$ of skin) present in the skin of dragon fruit, during different harvest times. 


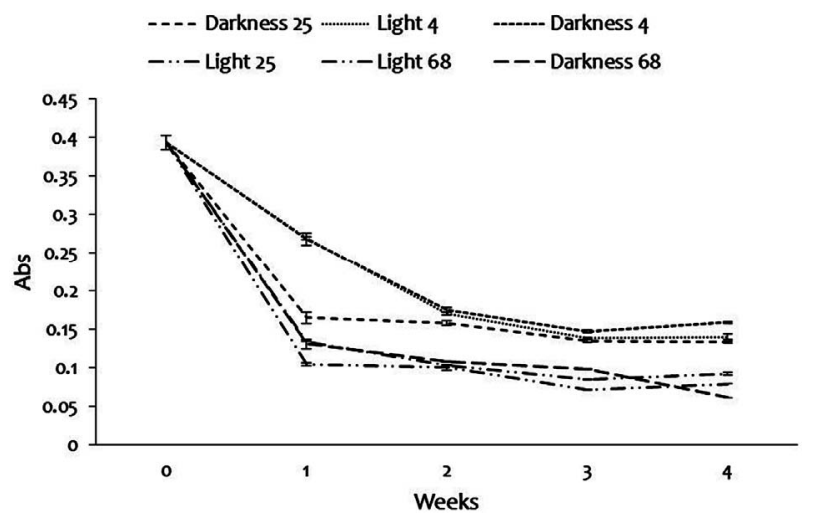

Figure 4. Effect of temperature and storage time in the absence and presence of light with $\mathrm{pH} 1$.

at $4^{\circ} \mathrm{C}$ from the second week; these three extracts were the ones which retained more pigment compared to the others. In the extracts kept at varying temperatures in the presence and absence of light and a $\mathrm{pH}$ of 4 , it was observed that under conditions of light and darkness at $25^{\circ} \mathrm{C}$ and $68^{\circ} \mathrm{C}$, a considerable decrease of absorbance occurred in the first week, showing no significant differences over the time of storage; this did not happen with the samples stored at $4^{\circ} \mathrm{C}$, both in light and in darkness, the extract that was kept in darkness being the most stable and the best preserved throughout the process (Figure 5). Figure 6 shows the same trend as in Figures 4 and 5, taking into account that the absorbances reported for this process were lower (in a range of 0.34 to 0.09 ) than those found at $\mathrm{pH} 1$ and 4 . The results obtained with $\mathrm{pH} 6$ indicate that the color is preserved longer at a temperature of $4^{\circ} \mathrm{C}$ than with higher temperatures, both in light and in darkness. One major environmental factor that affects the stability of the anthocyanin color is $\mathrm{pH}$. Anthocyanins are more stable in an acidic medium than in a neutral or alkaline one. In an acidic medium, the predominant form is that of the flavylium ion, which gives a red color when it is subjected to basic or alkaline $\mathrm{pH}$. The flavylium ion is susceptible to nucleophilic attack by water, producing, at $\mathrm{pH} 4.5$, the carbinol pseudobase, followed by chalcone; the two forms are colorless [30]. In our case, the extracts kept at $\mathrm{pH} 4$ and $4^{\circ} \mathrm{C}$, achieved a better retention of the pigment regardless of the presence or absence of light. At $\mathrm{pH} 4$ there will be a greater proportion of flavylium cation and, therefore, the solution is expected to be more stable at this $\mathrm{pH}$, with the colorant having a greater dyeing power due to an hyperchromic effect [31]. In the presence of oxygen, the maximum thermal stability of glycosylated anthocyanidin-3 occurs at $\mathrm{pH} 1.8$ to 2.0 , while for diglycosilated anthocyanidins-3,5 it occurs at $\mathrm{pH} 4.0-5.0$ [32]. At a pH between 2 and 4, the main path of degradation is hydrolysis of the sugar molecule. Knowing this, the anthocyanins extracted from dragon fruit skin attain their best color with an acid $\mathrm{pH}(\mathrm{pH} 4)$, so they must be of the type 3,5 diglycosilated; their colorless form occurs at a neutral or alkaline $\mathrm{pH}$, and because of this characteristic, anthocyanins are typically used in the food industry at an acid or slightly neutral $\mathrm{pH}$. The effect of temperature on anthocyanins is very important because the presence of heat during processing and storage degrades anthocyanins. There is a logarithmic relationship between the retention and intensity of color presented by solutions prepared using anthocyanins, and the temperature of the stabilization or storage processes [33]. Therefore, one option to improve the retention of the pigments is to apply hightemperature heat treatments of short duration, as well as storage at a low temperature. Timberlake [34] noted that the equilibrium between the structures is endothermic; from left to right:

\section{Quinoidal base $\leftrightarrow$ Favylium cation $\leftrightarrow$ Carbinol pseudobase $\leftrightarrow$ Chalcone}

At high temperatures, the equilibrium shifts to chalcones, which means loss of color. The return of chalcones to flavylium is slow [9]. Anthocyanin extracts showed greater stability at lower temperatures; this was evidenced because there was less discoloration of the extracts. Moreover, thermodynamic measurements show that the formation of the chalcone species from anthocyanin hemiacetal is endothermic $(\Delta \mathrm{H}=3.7 \mathrm{Kcal} / \mathrm{mol})$; therefore, any rise in temperature favors the increase of the chalcone form (colorless) present at equilibrium [35, 36 , which was confirmed by each of the samples, since at $4^{\circ} \mathrm{C}$ they were more stable than at $25^{\circ} \mathrm{C}$ and $68{ }^{\circ} \mathrm{C}$, with the same $\mathrm{pH}$ value. Thus, we can say that the anthocyanin aqueous extracts present in the skin of the dragon fruit will present greater stability and, in consequence, will behave best for natural consumption at low temperatures; the lower the temperature, the more stable will be the pigment.

Figure 7 shows the percentage of pigment retained in the extracts at the end of the four-week storage period. From this figure, it can be seen that with $\mathrm{pH} \mathrm{4}$, in the dark, at a temperature of $4^{\circ} \mathrm{C}$, it is possible to achieve a $80 \%$ pigment retention throughout the 4 weeks of storage; the extracts kept at the same temperature and $\mathrm{pH}$ in the presence of light retained $53 \%$ of the anthocyanins, whereas, at higher temperatures, in the presence or absence of light, regardless of $\mathrm{pH}$, pigment loss is significantly higher, retaining generally about $20 \%$ of the original residual anthocyanin. Retentions of $92 \%$ of anthocyanin pigments have been reported after 14 days of storage under conditions of darkness with a $\mathrm{pH}$ of 3 at a temperature of $4^{\circ} \mathrm{C}$, whereas with a $\mathrm{pH}$ of 6 and a tem- 


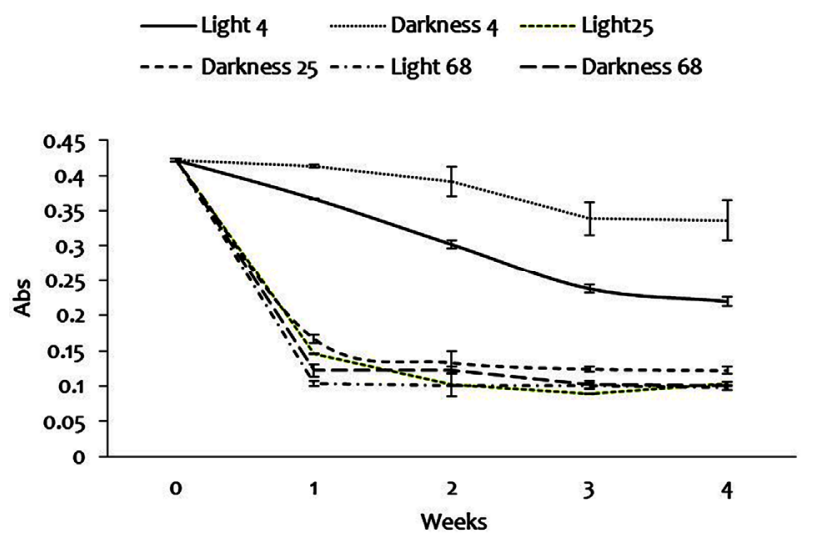

Figure 5. Temperature and storage time in the absence and presence of light with $\mathrm{pH} 4$.

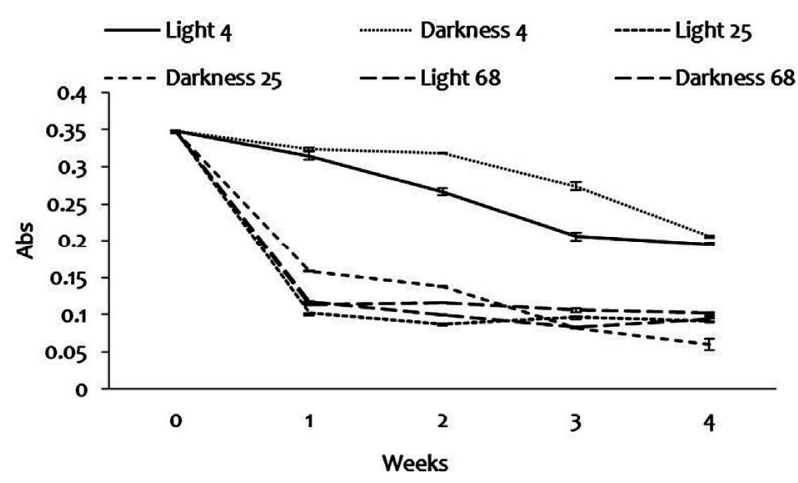

Figure 6. Temperature and storage time in the absence and presence of light with pH 6.

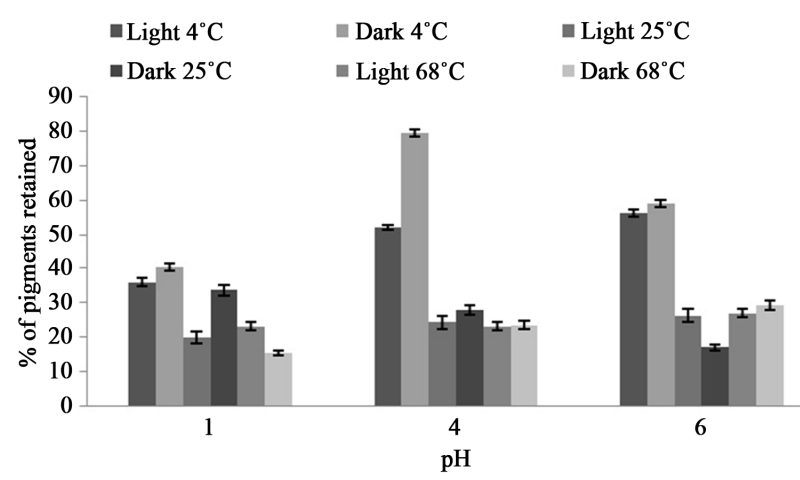

Figure 7. Percentage of pigments retained in extracts analyzed under different conditions of $\mathrm{pH}$, temperature and light.

perature of $4{ }^{\circ} \mathrm{C}$, the retention reported is $42 \%-61 \%$ in the same storage time [23]. An analysis of variance and a Duncan's multiple range test were performed on the obtained values to determine the stability of the pigment; the results indicated that $\mathrm{pH}$ and temperature have a statistically significant effect on the extracts maintained in the absence and presence of light with a confidence level of $95 \%$ and $\mathrm{p} \leq 0.05$ (Figure 8). The figure above shows the variability of the compound in different storage con-

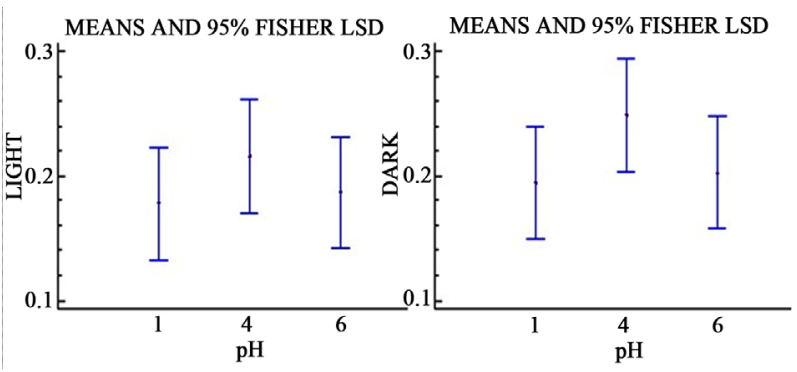

Figure 8. Comparison of the averages of absorbances between extracts stored in dark and light at different temperatures and $\mathrm{pH}$.

ditions ( $\mathrm{pH}$ and temperature). Duncan's multiple range method for comparing means shows that there is no significant difference between the absence and presence of light; however, temperature, $\mathrm{pH}$ and storage time are important factors in the variation of the absorbance of the compound, as the graphs show slight variations between retention of pigment in extracts stored under light and those stored in the darkness, the latter being the ones that present a smaller decrease in absorbance. The results show that anthocyanins remain stable at different $\mathrm{pH}$ because they do not show a statistically significant difference $(p=0.05)$. With respect to temperature, anthocyanins are unstable, since with higher temperatures $\left(68^{\circ} \mathrm{C}\right)$ the color degrades further, while at a lower temperature $\left(4^{\circ} \mathrm{C}\right)$ anthocyanins lose less color. This coincides with that reported by Gross (1987), who notes that anthocyanins are generally more stable in acidic media, in the absence of oxygen under refrigeration and in the dark; this is related to the decrease of anthocyanin content at $\mathrm{pH} 4,4^{\circ} \mathrm{C}$ and in the dark. Palamadis and Markakis [37] report that in the dark, at $38^{\circ} \mathrm{C}$, after 135 days, only $23 \%$ of the original amount of pigment extracted with hot water remained in a drink, while at $3.5^{\circ} \mathrm{C}$, under the same conditions of storage, $92 \%$ of the pigment was retained, so the results obtained from the study of the stability of anthocyanins found in dragon fruit skin indicate that during the period of time established, a greater amount of pigment is retained in the dark at low temperatures $\left(4^{\circ} \mathrm{C}\right)$, and although there is no significant difference with respect to $\mathrm{pH}$, retention is statistically greater at $\mathrm{pH} 4$.

\subsection{Partial Identification of Anthocyanins Present in the Skin of the Dragon Fruit}

Once the extraction process has been completed, it is necessary to submit the sample to a purification process to remove substances such as lipids, carotenoids and chlorophyll that could interfere with subsequent qualitative and quantitative analyzes [38,39]. A technique commonly used to purify is solid phase extraction (SPE) with $\mathrm{C}_{18}$ or Sephadex. Free hydroxyl groups of anthocyanins 
are strongly retained by the cartridge matrix, requiring polar gradients to elute phenolic compounds. Thus, Talcott [25] proposes that SPE is an appropriate technique for removing hydrophilic compounds (among these, sugars and certain organic acids) that may interfere with subsequent analyzes; the advantage of the $\mathrm{C} 18$ cartridges is their lower porosity and greater load capacity. The purified extracts containing anthocyanins were analyzed by HPLC; the chromatogram of the standard mixture is shown in Figure 9, where the first peak corresponds to pelargonidin with a retention time of 11.098 minutes; the second corresponds to cyanidin 3 O-glucoside and the third to malvidin, with retention times of 16.22 and 46.25 minutes respectively.

A large number of peaks were observed in the chromatograms from the extracts of dragon fruit skin that could not be identified. Three anthocyanins could be identified according to commercial standards: 3,5 O diglucoside, pelargonidin 3,5 O-di glucoside and cyanidin $3 \mathrm{O}-$ glucoside; they presented retention times of 6.12, 11.09 and 16.22 minutes, respectively, coinciding with the standards used for identification.

\section{Conclusions}

It is possible to extract anthocyanins from the skin of the dragon fruit satisfactorily with acidified methanol, $1 \%$ trifluoroacetic acid (TFA) and a mixture of methanol: acetic acid-water. From the study conducted to determine the stability of the pigments under controlled conditions of temperature, $\mathrm{pH}$, presence and absence of light, during a storage time of 4 weeks, it can be concluded that the best combination of these factors for anthocyanins is a temperature of $4^{\circ} \mathrm{C}$ in the absence of light and a $\mathrm{pH}$ equal to 4 .

This research could be very important from an economic and industrial point of view, because the inside of the dragon fruit (pulp) can be used for industrial applications such as the manufacture of minimally processed natural juices, jams etc., while the skin, which is now

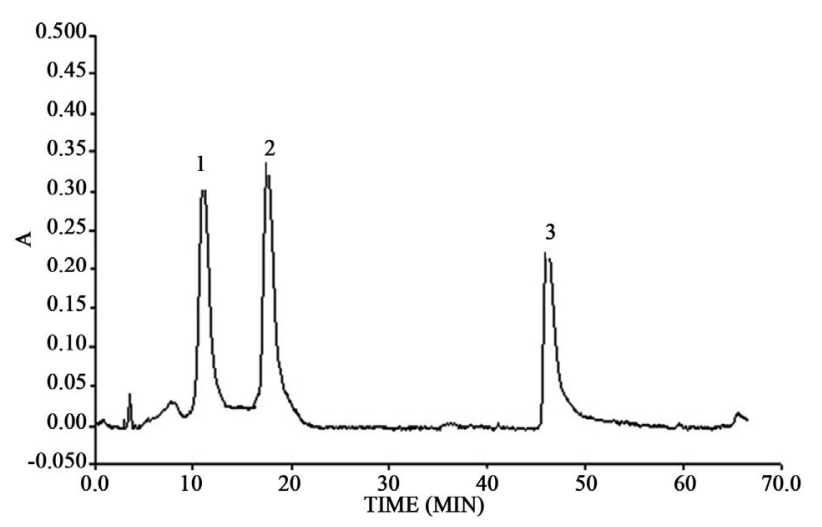

Figure 9. Chromatogram of anthocyanin standards. treated as a waste product, would be useful as a source of anthocyanin colorants, helping to lower costs in the production of colorants and to obtain a safe product with antioxidant potential.

\section{REFERENCES}

[1] G. Del Valle, A. González and R. Báez, “Antocianinas en Uva (Vitis vinifera) y su Relación con el Color," Revista de Fitotecnología, Vol. 28, No. 1, 2005, pp. 359-368.

[2] O. Anderson and G. Francis, "Techniques of Pigment Identification," Annual Plant Reviews-Plant Pigments and Their Manipulation, Vol. 14, 2004, pp. 293-341.

[3] G. Garzón, "Las Antocianinas como Colorantes Naturales y Compuestos Bioactivos," Revisión. Acta Biol. Colombia, Vol. 13, No. 3, 2008, pp. 27-36.

[4] J. Walford, "Developments in Food Colors," Applied Science Publishers, London, 1980, pp. 116-142.

[5] J. Gross, "Pigments in fruits," Academic Press, London, 1987.

[6] J. J. Macheix, A. Fleuriet and J. Billot, "Fruit Phenolics," CRC Press, Florida, 1990, pp. 1-17,39-81,105-149.

[7] R. E. Wrostald, R. W. Durst and J. Lee, "Tracking Color and Pigment Changes in Anthocyanin Products," Trends in Food Science and Technology, Vol. 16, No. 9, 2005, pp. 423-428. http://dx.doi.org/10.1016/j.tifs.2005.03.019

[8] L. E. Rodriguez-Saona and R. E. Wrolstad, "Extraction, Isolation and Purification of Anthocyanins," In: Current Protocols in Food Analytical Chemistral, John Wiley and sons, New York, 2001, pp. 1-11. http://dx.doi.org/10.1002/0471142913.faf0101s00

[9] M. E. Cuevas, A. Antezana and P. Winterhalter, "Análisis y Caracterización de Antocianinas en Diferentes Variedades de Maíz (Zea mays) Boliviano," In: Memorias Red-Alfa Lagrotech, Comunidad Europea, Cartagena, Colombia, 2008, pp. 79-95.

[10] J. B. Harborne and R. J. Grayer., "The Anthocyanins," In: Harborne Although the Hemical Structure of Anthocyanins. The flavonoids: Advances in Research since 1980, Chapman and Hall, London, 1988, pp. 1-20.

[11] V. Hong and R. E. Wrolstad, "Use of HPLC Separation/ Photodiode Array Detection for Characterization of Anthocyanins," Journal of Agricultural and Food Chemistry, Vol. 38, No. 3, 1990, pp. 708-715. http://dx.doi.org/10.1021/jf00093a026

[12] A. Hagiwara, H. Yoshino, T. Ichiharam, M. Kawabe, S. Tamano, H. Aoki, T. Koda, M. Nakamura, K. Imaida, N. Ito and T. Shirai, "Prevention by Natural Food Anthocyanins, Purple Sweet Potato Color and Red Cabbage Color, of 2-Amino-1-Methyl-6-Phenylimidazo[4,5-B]Pyridine (Phip)-Associated Colorectal Carcinogenesis in Rats," The Journal of Toxicological Sciences, Vol. 27, No. 1, 2002, pp. 57-68. http://dx.doi.org/10.2131/jts.27.57

[13] F. Tristan, B. Kraft, B. M. Schmidt, G. G. Yousef, C. T. G. Knigh, M. Cuendet, Y. H. Kang, J. M. Pezzuto, D. S. Seigler and M. A. Lila, "Chemopreventive Potential of Wild Lowbush Blueberry Fruits in Multiple Stages of Carcinogenesis," Journal of Food Science, Vol. 70, No. 3, 
2005, pp. s159-s166.

[14] J. Wang and G. Mazza, "Inhibitory Effects of Anthocyanins and Other Phenolic Compounds on Nitric Oxide Production in LPS/IFN Gamma-Activated RAW 264.7 Macrophages," Journal of Agricultural and Food Chemistry, Vol. 50, No. 4, 2002, pp. 850-857. http://dx.doi.org/10.1021/jf010976a

[15] R. Moyer, K. Hummer, Ch. Finn, B. Frei and R. Wrolstad, "Anthocyanins. Phenolics, and Antioxidant Capacity in Diverse Small Fruits: Vaccinium, Rubus, and Ribes," Journal of Agricultural and Food Chemistry, Vol. 50, No. 3, 2002, pp. 519-525. http://dx.doi.org/10.1021/jf011062r

[16] R. E. Wrolstad, “Anthocyanins," In: Natural Food Colorants, Marcel Dekker, New York, 2000, pp. 237-252.

[17] B. A. Cevallos-Casals and L. Cisneros-Zeballos, "Stability of Anthocyanin Based Aqueous Extract of Andean Purple Corn and Red Fleshed Sweet Potato Compared to Synthetic and Natural Colorants," Food Chemistry, Vol. 86, No. 1, 2004, pp. 69-77.

http://dx.doi.org/10.1016/j.foodchem.2003.08.011

[18] H. Y. D. Ortiz, "Hacia el Conocimiento de la Conservación de la Pitahaya," México, 2000, p. 124.

[19] A. R. Centurión, S. Solís, V. C. Saucedo, S. R. Báez and E. Sauri, "Cambios Físicos, Químicos y Sensoriales en Frutos de Pitahaya (Hylocreus undatus) Durante su Desarrollo," Fitotecnia Mexicana, Vol. 31, No. 1, 2008, pp. $1-5$.

[20] V. E. Chan, "Variación de Color y del Contenido de Pigmentos del Epicarpio de la Pitahaya (Hilocereus undatus)," Masters Thesis, Instituto Tecnológico de Mérida, México, 2006.

[21] G. R. McGuire, "Reporting of Objective Color Measurements," HortScience, Vol. 27, No. 12, 1992, pp. 12541255.

[22] G. Peña, Y. Salinas and R. Ríos, "Contenido de Antocianinas Totales y Actividad Antioxidante en Frutos de Frambuesa (Rubus idaeus L.) con Diferentes Grados de Maduración," Revista Chapingo Serie Horticultura, Vol. 12, No. 2, 2006, pp. 159-163.

[23] M. G. Aguilera, C. L. Alanis, C. M. García and B. Hernández, "Caracterización y Estabilidad de Antocianinas de Higo, Variedad Mission," Universidad y Ciencia, Vol. 25, No. 2, 2009, pp. 151-158.

[24] C. Brenes, D. Pozo and S. Talcott, "Stability of Copigmented Anthocyanins and Ascorbic Acid in a Grape Juice Model System," Journal of Agricultural and Food Chemistry, Vol. 53, No. 1, 2005, pp. 49-56. http://dx.doi.org/10.1021/jf049857w

[25] S. Talcott and J. Lee, "Ellagic Acid and Flavonoid Antioxidant Content of Muscadine Wine and Juice," Journal of Agricultural and Food Chemistry, Vol. 50, No. 11, 2002, pp. 3186-3192. http://dx.doi.org/10.1021/jf011500u

[26] A. Nerd, F. Gutman and Y. Mizrahi, "Ripening and Postharvest Behavior of Fruits of Two Hylocereus Species (Cactaceae)," Postharvest Biology and Technology, Vol.
17, No. 1,1999 , pp. $39-45$. http://dx.doi.org/10.1016/S0925-5214(99)00035-6

[27] J. M. Anttonen and O. R. Karjalainen, "Environmental and Genetic Varation of Phenolic Compounds in Red Raspberry," Journal of Food Composition and Analysis, Vol. 18, No. 8, 2005, pp. 759-769.

http://dx.doi.org/10.1016/j.jfca.2004.11.003

[28] Y. Salinas, L. Herrera, S. Montes and P. Herrera, "Composición de Antocianinas en Variedades de Frijol Negro (Phaseolus vulgaris L.) Cultivadas en México," Agrociencia, Vol. 39, No. 4, 2005, pp. 385-394.

[29] T. Fuleki and F. J. Francis, "Quantitative Methods for Anthocyanins Extraction and Determination of Total Anthocyanins in cranberries," Journal of Food Science, Vol. 33, No. 1, 1968, pp. 72-77. http://dx.doi.org/10.1111/j.1365-2621.1968.tb00887.x

[30] J. Hutchings, "Food Color and Appearance," Aspen Publishers, Washington DC, 1999. http://dx.doi.org/10.1007/978-1-4615-2373-4

[31] G. Mazza, "Anthocyanin in Grapes and Grape Products," Critical Reviews in Food Science and Nutrition, Vol. 35, No. 4, 1995, pp. 341-371. http://dx.doi.org/10.1080/10408399509527704

[32] O. Ugaz, "Colorantes Naturales," Fondo Editorial de la Pontificia Universidad Católica del Perú, Perú, 1997.

[33] S. Badui, "Química de los Alimentos," Pearson Educación, México, 2006.

[34] C. F. Timberlake and B. S. Henry, "Plant Pigments as Natural Food Colours," Endeavour NS, 1986, pp. 31-36.

[35] R. Brouillard and B. Delaporte, "Chemistry of Anthocyanin Pigments. 2 Kinetic and Thermodynamic Study of Proton Transfer, Hydration, and Tautometric Reactions of Malvidin 3-Glucoside," Journal of the American Chemical Society, Vol. 99, No. 26, 1977, pp. 8461-8468. http://dx.doi.org/10.1021/ja00468a015

[36] R. Brouillard, G. Mazza, Z. Saad, A. M. Albrecht-Gray and A. Cheminat, "The Copigmentation Reaction of Anthocyanins: A Microprobe for the Structural Study of Aqueous Solutions," Journal of the American Chemical Society, Vol. 111, No. 7, 1989, pp. 2604-2610. http://dx.doi.org/10.1021/ja00189a039

[37] N. Palamadis and P. Markakis, "Stability of Grape Anthocyanin in a Carbonated Beverage," Journal of Food Science, Vol. 40, No. 5, 1975, pp. 1047-1049. http://dx.doi.org/10.1111/j.1365-2621.1975.tb02264.x

[38] P. L. Buldini, S. Cavalli and J. L. Sharma, "Matrix Removal for the Ion Chromatographic Determination of Some Trace Elements in Milk," Microchemical Journal, Vol. 72, No. 3, 2002, pp. 277-284. http://dx.doi.org/10.1016/S0026-265X(02)00039-5

[39] S. Pascual-Teresa, J. C. Rivas and C. Santos, "Prodelphinidins and Related Flavanols in Wine," International Journal of Food Science and Technology, Vol. 35, No. 1, 2000, pp. 33-40. http://dx.doi.org/10.1046/j.1365-2621.2000.00338.x 